\title{
CINÉTICA DE DEGRADAÇÃO DA MATÉRIA ORGÂNICA DE BIOSSÓlidOS APÓS APLICAÇÃO NO SOLO E RELAÇÃO COM A COMPOSIÇÃO QUÍMICA INICIAL $\left(^{(1)}\right.$
}

\author{
CRISTIANO ALBERTO DE ANDRADE $\left({ }^{2 *}\right)$; CLAUDEIR DE OLIVEIRA $\left({ }^{3}\right)$; CARLOS CLEMENTE CERRI $\left({ }^{4}\right)$
}

\begin{abstract}
RESUMO
O objetivo deste estudo foi avaliar a degradação de biossólidos após aplicação no solo, relacionando com a composição química inicial da matéria orgânica (MO) desses resíduos. Foram utilizados quatro biossólidos e um composto orgânico à base de lodo de esgoto, provenientes de diferentes sistemas de tratamento de esgotos e/ou estabilização do lodo e/ou condicionamento químico para desidratação e/ ou etapa complementar visando à melhor adequação ao uso agrícola. A degradação dos biossólidos foi determinada com quantificação do $\mathrm{CO}_{2}$ emanado a partir de experimento de incubação de misturas de amostras de um Latossolo, com dose dos resíduos correspondente a $40 \mathrm{t} \mathrm{ha}^{-1}$. As taxas de degradação da fração orgânica dos resíduos variaram entre 5\% e $22 \%$. De modo geral, a degradação da fração orgânica dos biossólidos foi descrita por equação de cinética química com duas fases: a primeira fase caracterizou-se pela elevada velocidade de degradação de compostos orgânicos presentes em quantidades limitadas, cuja exaustão do substrato ocorreu em poucos dias (2 a 20 dias); a segunda fase caracterizou-se pela redução da velocidade da reação de degradação e aumento da quantidade de carbono mineralizado (65\% do total de C mineralizado no período). A proteína bruta, expressa como porcentagem do conteúdo orgânico dos resíduos, foi o parâmetro que melhor correlacionou com a taxa de degradação dos biossólidos no fim de 70 dias de incubação $\left(r=0,999\right.$ e Prob. $>$ t inferior a $\left.10^{-4}\right)$, sendo promissora sua utilização na previsão da taxa de degradação da MO de biossólidos após aplicação no solo. A participação do compartimento protéico foi crescente com o tempo de incubação, comprovando que no início do período de avaliação outros compostos orgânicos mais lábeis funcionaram como fonte de carbono e de energia para a microbiota edáfica.
\end{abstract}

Palavras-chave: lodo de esgoto, carbono, proteína, decomposição, cinética química, compostos orgânicos.

$\left(^{1}\right)$ Trabalho extraído da Tese de Doutorado do primeiro autor. Programa de Solos e Nutrição de Plantas da Escola Superior de Agricultutra "Luiz de Queiroz", ESALQ/USP. Recebido para publicação em 17 de junho de 2005 e aceito em 15 de julho de 2006.

$\left({ }^{2}\right)$ Centro de Solos e Recursos Ambientais. Instituto Agronômico (IAC) - Av. Barão de Itapura, 1481. Caixa Postal 28, 13020-902 Campinas (SP). E-mail: andrade@iac.sp.gov.br. *Autor correspondente

$\left({ }^{3}\right)$ Escola Superior de Agricultura "Luiz de Queiroz" - Setor de Química Analítica. Av. Pádua Dias, 11. 13418-900 Piracicaba (SP). E-mail: colivei@esalq.usp.br

$\left({ }^{4}\right)$ Centro de Energia Nuclear na Agricultura - Laboratório de Biogeoquímica Ambiental. Av. Centenário, 303. 13400-961 Piracicaba (SP). E-mail: cerri@cena.usp.br 


\section{ABSTRACT \\ DEGRADATION KINETICS OF BIOSOLIDS ORGANIC MATTER AFTER SOIL APPLICATION AND ITS RELATIONSHIP WITH INITIAL CHEMICAL COMPOSITION}

The aim of this study was to evaluate biosolids degradation after soil application, in relation to the initial organic matter $(\mathrm{OM})$ chemical composition of the residue. Four biosolids and sewage sludge compost differentiated by being originated from different waste systems and/or sludge stabilization process and/or chemical conditioning to dehydration and/or additional treatment to adequate the residue for agricultural application were used. Biosolids degradation was determinated in a experiment done to quantify $\mathrm{CO}_{2}$ emitted from Oxisol samples incubated with biosolids in a dose correspondent to $40 \mathrm{tha}{ }^{-1}$. The degradation rates of biosolids organic matter were between $5 \%-22 \%$. In general, the biosolids organic matter decomposition was described by a two-stage equation of chemical kinetics: the first stage showed high decomposition velocity and organic compounds exhausted in few days (2 to 20 days); whereas the second stage had a reduced decomposition velocity in comparison to the first phase, and a relative increase of mineralized carbon ( ${ }^{3} 65 \%$ of total degraded carbon during all incubation period). Gross protein, expressed as organic residue content, was the parameter better correlated with biosolids degradation rate at the end of 70 days of incubation $\left(r=0.999\right.$ e Prob. $>t$ lower than $\left.10^{-4}\right)$, its utilization being prospective to biosolids organic matter degradation after addition to soils. Protein pool participation increased with incubation time, indicating that in the beginning of the experiment more labile organic compounds worked as carbon and energy sources for the edafic microbiota.

Key words: sewage sludge, carbon, protein, decomposition, chemical kinetic, organic compounds.

\section{INTRODUÇÃO}

Programas visando à reciclagem agrícola de biossólidos representam uma alternativa para minimizar o problema de disposição final desse material, bem como prevenir contra efeitos adversos no ambiente, prezando pela conservação dos recursos naturais e por benefícios agronômicos. Por esse motivo, a dinâmica da matéria orgânica (MO) de biossólidos após aplicação no solo merece especial atenção, uma vez que interfere no ciclo do carbono do solo (GILMOur et al., 1996), na disponibilidade de nutrientes (Franco-Hernández et al., 2003) e de elementos potencialmente tóxicos (Bertoncini, 2002).

A degradação de resíduos orgânicos em geral, após aplicação no solo, é influenciada por fatores relacionados ao resíduo, ao solo e ao clima (Ajwa e TаватаваI, 1994). No caso específico de biossólidos, têm-se verificado que características do resíduo e condições de temperatura e umidade são mais determinantes da taxa de degradação, do que o tipo de solo (SOMmers et al., 1979). Algumas características dos biossólidos reconhecidamente importantes no estabelecimento da taxa de degradação são: $\mathrm{pH}$, conteúdo de nutrientes, teor de $\mathrm{C}$, concentração de sais solúveis, teores de metais pesados e composição química da fração orgânica (HATTORI e MUKAI, 1986).

$\mathrm{O}$ aporte de $\mathrm{C}$ ao solo via biossólido, embora tenha correlação positiva com a quantidade absoluta de carbono emanado como $\mathrm{CO}_{2}\left(\mathrm{C}-\mathrm{CO}_{2}\right)$, pode correlacionar inversamente com a taxa de degradação
(SANTOS et al., 2002). Uma possível explicação para esse fato relaciona-se com o aumento do conteúdo orgânico adicionado, suplantando a capacidade microbiana de degradação (WONG et al., 1998). Outra possibilidade seria o aumento excessivo da taxa de respiração da comunidade microbiana edáfica, em função do maior aporte de formas lábeis de $\mathrm{C}$ com o aumento da dose do resíduo, o que causaria uma condição de anaerobiose temporária no solo, reduzindo a taxa de degradação (KHALIL et al., 2002).

Tão importante quanto o aporte de $\mathrm{C}$ ao solo via biossólido, é a qualidade do material introduzido, isto é, a composição da MO do resíduo. A abundância relativa dos compostos orgânicos (carboidratos, lipídios, aminoácidos, lignina, etc.) presentes na MO determina parcialmente sua taxa de degradação após aplicação no campo (Hattori e MUKai, 1986; Bernal et al., 1998). Informações a esse respeito são escassas na literatura, notadamente no que se refere às relações entre composição química da $\mathrm{MO}$ de biossólidos e taxa de degradação.

Atualmente, a taxa de degradação de resíduos orgânicos tem sido determinada sob condições controladas de temperatura e umidade, em que misturas de solo e resíduo, e somente solo (controle), são incubados por períodos variáveis de 60 a 90 dias, medindo-se periodicamente a quantidade de $\mathrm{C}-\mathrm{CO}_{2}$ emanada. Esses experimentos, denominados respirométricos, são de longa duração e custo relativamente elevado. 
A quantificação e o uso de alguns compostos orgânicos, ou índices calculados a partir destes, na previsão da degradação de biossólidos no solo, pode reduzir custos (mão-de-obra e tempo), facilitar o acesso à informação e, conseqüentemente, ao uso agrícola do resíduo.

O objetivo do presente estudo foi avaliar a degradação de biossólidos após aplicação no solo, identificando diferentes fases do processo e relacionando com a composição química inicial da $\mathrm{MO}$ desses resíduos.

\section{MATERIAL E MÉTODOS}

\subsection{Solo e biossólidos}

O solo utilizado foi um Latossolo Vermelho eutroférrico de textura argilosa, coletado de área sob cultivo de cana-de-açúcar, no município de Santa Bárbara d'Oeste (SP). Todo volume de solo coletado foi seco ao ar, peneirado em peneira com abertura de malha de $2 \mathrm{~mm}$ (TFSA), homogeneizado e reservado para as incubações. Algumas características químicas do solo para fins de fertilidade, determinadas conforme descrito em Raij et al. (2001), foram: $\mathrm{pH}=5,2 ; \mathrm{MO}=28 \mathrm{~g} \mathrm{dm}^{-3} ; \mathrm{K}=0,6 \mathrm{mmol}_{\mathrm{c}}$ $\mathrm{dm}^{-3} ; \mathrm{Ca}=6 \mathrm{mmol}_{\mathrm{c}} \mathrm{dm}^{-3} ; \mathrm{Mg}=2 \mathrm{mmol}_{\mathrm{c}} \mathrm{dm}^{-3} ; \mathrm{Al}=6$ $\operatorname{mmol}_{\mathrm{c}} \mathrm{dm}^{-3} ; \mathrm{H}+\mathrm{Al}=14 \mathrm{mmol}_{\mathrm{C}} \mathrm{dm}^{-3} ; \mathrm{SB}=8,6 \mathrm{mmol}_{\mathrm{c}}$ $\mathrm{dm}^{-3} ; \mathrm{CTC}=22,6 \mathrm{mmol}_{\mathrm{c}} \mathrm{dm}^{-3} ; \mathrm{V}=38 \%$; e $\mathrm{m}=41 \%$.

Foram utilizados quatro biossólidos e um composto orgânico à base de lodo de esgoto, bagaço de cana-de-açúcar e resto de poda urbana (Tabela 1).

Os biossólidos anaeróbios (BAC, BAS e BLP) foram provenientes da Estação de Tratamento de Esgotos (ETE) de Barueri/SABESP, em Barueri (SP), que trata dos esgotos da maior parte da cidade de São Paulo e dos municípios de Jandira, Itapevi, Barueri, Carapicuíba, Osasco, Taboão da Serra e partes de Cotia e Embu. O BLP foi obtido junto a ETE de Jundiaí/CSJ que trata dos esgotos do município de Jundiaí (SP).
A escolha dos biossólidos ocorreu em função de diferenças nos processos geradores, em termos de: sistema de tratamento de esgotos, processo para estabilização do lodo, alternativa de condicionamento químico para desidratação dos biossólidos e etapa complementar visando melhor adequação dos resíduos ao uso agrícola.

\subsection{Experimento para avaliação da degradação dos biossólidos}

Amostras de $300 \mathrm{~g}$ de TFSA foram incubadas com os biossólidos, em potes de vidro (1,5 L), durante um período de 70 dias, no escuro, à temperatura de 28 $\pm 1^{\circ} \mathrm{C}$ e umidade correspondente a $60 \%$ da capacidade de campo das misturas. O preparo das amostras dos biossólidos para uso no experimento consistiu em secagem a $40^{\circ} \mathrm{C}$ e posterior moagem, passando em peneira com abertura de malha de $0,84 \mathrm{~mm}$.

Os tratamentos testados foram em número de oito, além do controle (somente TFSA), com três repetições cada um, no total de 27 unidades experimentais, dispostas inteiramente ao acaso para incubação. A dose referência escolhida para comparação dos biossólidos foi o equivalente a $40 \mathrm{t} \mathrm{ha}^{-1}$ (base seca) e, somente para o BAP, doses equivalentes a 10, 20 e $80 \mathrm{t} \mathrm{ha}^{-1}$ (base seca) também foram testadas.

A avaliação da degradação dos biossólidos após mistura com o solo foi feita por meio da avaliação do $\mathrm{CO}_{2}$ emanado. Seguiu-se o método recomendado pela Companhia de Tecnologia de Saneamento Ambiental - CETESB, Norma Técnica P4.230 (CETESB, 1999), com captura do $\mathrm{CO}_{2}$ emanado por solução padronizada de $\mathrm{NaOH} 0,5 \mathrm{~mol} \mathrm{~L}^{-1}$. Houve troca periódica da solução de $\mathrm{NaOH}$ contida no interior dos potes, encaminhando imediatamente aquelas retiradas para quantificação do $\mathrm{CO}_{2}$, realizada por meio de leitura da condutividade elétrica (RODELla e SABOya, 1999).

Tabela 1. Biossólidos utilizados no experimento: sistema de tratamento dos esgotos nas estações, condicionamento químico para desidratação e etapa complementar para melhor adequação ao uso agrícola.

\begin{tabular}{|c|c|c|c|}
\hline Biossólido & Tratamento dos esgotos & Condicionamento químico & Etapa complementar \\
\hline BAC & Lodos ativados; reator anaeróbio & Cal hidratada e cloreto férrico & Desidratação mecânica \\
\hline B AP & Lodos ativados; reator anaeróbio & Polímero sintético & Desidratação mecânica \\
\hline BAS & Lodos ativados; reator anaeróbio & Polímero sintético & $\begin{array}{l}\text { Secagem térmica, sem superaquecimento } \\
\text { dos grânulos de lodo ( } 70 \text { minutos) }\end{array}$ \\
\hline BLP & $\begin{array}{l}\text { Lagoas aeradas, seguidas } \\
\text { de lagoas de decantação } \\
\text { (idade média } 1 \text { ano) }\end{array}$ & Polímero sintético & $\begin{array}{l}\text { Secagem em leitos com revolvimento } \\
\text { periódico (120 dias) }\end{array}$ \\
\hline CL & $\begin{array}{l}\text { Lagoas aeradas, seguidas } \\
\text { de lagoas de decantação } \\
\text { (idade média } 1 \text { ano) }\end{array}$ & Polímero sintético & $\begin{array}{l}\text { Compostagem com bagaço de cana e restos } \\
\text { de poda urbana ( } 90 \text { dias) }\end{array}$ \\
\hline
\end{tabular}

\footnotetext{
a BAC = biossólido anaeróbio condicionado com cal e cloreto férrico; BAP = biossólido anaeróbio condicionado com polímero sintético; BAS = biossólido anaeróbio seco termicamente; BLP = biossólido proveniente de lagoas de estabilização e condicionado com polímero sintético; e CL = composto de lodo de esgoto obtido por compostagem em pilhas aeradas após mistura do BLP com bagaço de cana e restos de poda urbana.
} 


\subsection{Forma de análise dos resultados}

O carbono degradado dos resíduos ( $\mathrm{C}$ degradado) foi obtido a partir do $\mathrm{C}-\mathrm{CO}_{2}$ emanado acumulado em cada tratamento e tempo, descontado o controle.

Os dados de C-degradado foram usados em ajustes tentativos às equações de cinética química de primeira ordem, com uma, duas e três fases, para obtenção dos valores de C potencialmente mineralizável, constante de velocidade da reação de degradação e meiavida de degradação (T1/2 = ln 2 / k), bem como verificar a ocorrência de fases distintas durante a degradação da MO dos biossólidos. Na seqüência são apresentadas as equações de cinética química utilizadas.

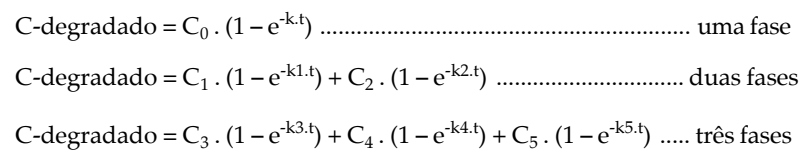

\section{Em que:}

C-degradado = quantidade de carbono $\left(\mathrm{mg} \mathrm{kg}^{-1}\right)$ emanada na forma de $\mathrm{CO}_{2}$ no tempo $t ;(1,2$ e 3$)$

$\mathrm{C}_{0}=$ carbono $\left(\mathrm{mg} \mathrm{kg}^{-1}\right)$ potencialmente mineralizável em 70 dias de incubação; (1)

k = constante de velocidade da reação de degradação do carbono orgânico do biossólido $\left(\right.$ dia $\left.^{-1}\right) ;(1)$

$\mathrm{t}$ = tempo de incubação em dias; $(1,2$ e 3$)$

$\mathrm{C}_{1}$ e $\mathrm{C}_{2}=$ carbono $\left(\mathrm{mg} \mathrm{kg}^{-1}\right)$ potencialmente mineralizável durante, respectivamente, a primeira e segunda fases do processo de degradação do carbono do biossólido descrito pela equação bifásica; (2)

$\mathrm{k}_{1}$ e $\mathrm{k}_{2}=$ constante de velocidade da reação de degradação do carbono orgânico do biossólido $\left(\mathrm{dia}^{-1}\right)$ durante a primeira e segunda fases de degradação respectivamente; (2)

$\mathrm{C}_{3}, \mathrm{C}_{4}$ e $\mathrm{C}_{5}=$ carbono $\left(\mathrm{mg} \mathrm{kg}^{-1}\right)$ potencialmente mineralizável durante, respectivamente, a primeira, segunda e terceira fases do processo de degradação do carbono do biossólido descrito pela equação trifásica; (3)

$\mathrm{k}_{3}, \mathrm{k}_{4}$ e $\mathrm{k}_{5}=$ constante de velocidade da reação de degradação do carbono orgânico do biossólido $\left(\mathrm{dia}^{-1}\right)$ durante a primeira, segunda e terceira fases de degradação respectivamente; (3)

As taxas de degradação dos biossólidos, determinadas no fim do período de incubação, foram correlacionadas com os resultados da caracterização química da $\mathrm{MO}$ dos resíduos (Tabela 2), sendo esta realizada por meio de seqüências complexas de digestões e extrações, originalmente desenvolvidas para análises de forrageiras e madeira. Os teores de lipídeos e proteína bruta foram determinados conforme recomendação da Association of Official Analytical Chemists (1995), enquanto os carboidratos, a celulose, a hemicelulose, a lignina, os taninos e os fenóis foram quantificados conforme descrito em VAN SOEST e Wine (1967).

Além dos compostos orgânicos determinados na MO dos resíduos, foram também testados alguns índices para previsão da degradação do $\mathrm{C}$ dos biossólidos, sendo eles: relação $\mathrm{C} / \mathrm{N}$; relação Lignina /
N; Índice Lignocelulósico (ILC), que é a relação entre lignina e lignina + celulose; Quociente Holocelulose / Lignocelulose (QHL), calculado como a relação entre hemicelulose + celulose e hemicelulose + celulose + lignina; e Razão de Carbono Oxidável (RCO), que é a relação entre C-total determinado por combustão a seco em analisador Leco CN-2000 e C determinado pelo método Walkley-Black.

Todas as correlações foram realizadas utilizando-se os valores médios.

\section{RESULTADOS E DISCUSSÃO}

\subsection{Degradação da MO dos biossólidos}

Na dose referência de $40 \mathrm{t} \mathrm{ha}^{-1}$, os biossólidos provenientes de reator anaeróbio foram aqueles com maiores valores de $\mathrm{C}-\mathrm{CO}_{2}$ emanado, enquanto o biossólido compostado (CL) apresentou os menores valores (Figura 1A). Durante os primeiros dez dias de incubação, o BAS e o BAP proporcionaram semelhante liberação de $\mathrm{C}-\mathrm{CO}_{2}$, diferindo posteriormente, com maior liberação no tratamento com BAS. Nesse período inicial, no tratamento com o BAC houve pequena liberação de $\mathrm{C}-\mathrm{CO}_{2}$, sendo inclusive inferior ao CL durante os sete primeiros dias. A incorporação do BAC induziu a chamada lag-fase, uma fase de adaptação da comunidade microbiana às novas condições do meio. A indução da lag-fase verificada no solo tratado com o BAC pode ter ocorrido devido a elevada alcalinidade do resíduo e/ou teor de sais solúveis, uma vez que a origem, o tratamento dos esgotos e o processo de estabilização do lodo são os mesmos do BAS e BAP, somente diferindo quanto ao condicionamento químico para desidratação (Tabela 1).

Comparando-se as quantidades totais de C- $\mathrm{CO}_{2}$ emanadas a partir das amostras de solo tratadas com BLP e com CL, no fim do período de incubação (Figura 1A), 1564 e $954 \mathrm{mg} \mathrm{kg}^{-1}$, respectivamente, podese verificar que o processo de compostagem do biossólido proporcionou redução da quantidade de C$\mathrm{CO}_{2}$ emanada da mistura solo/resíduo, em comparação ao biossólido não compostado.

A aplicação de até $80 \mathrm{t} \mathrm{ha}^{-1}$ do BAP proporcionou incrementos nas quantidades de $\mathrm{C}-\mathrm{CO}_{2}$ emanadas das misturas (Figura 1B), o que é consistente com o observado em outros trabalhos da literatura (Hattori e Mukai, 1986; Pires et al., 2002; SANTOS et al., 2002).

As diferenças verificadas entre as quantidades de $\mathrm{C}-\mathrm{CO}_{2}$ emanadas dos tratamentos com biossólidos e do solo controle, indicam a contribuição positiva dos resíduos na atividade microbiana edáfica. 
Tabela 2. Valores médios dos teores matéria orgânica (MO), carbono (C) e nitrogênio, expressos em relação a massa seca dos biossólidos, e de carbono solúvel em água e alguns compostos orgânicos, expressos em relação ao total de $\mathrm{C}$ ou $\mathrm{MO}$ dos resíduos.

\begin{tabular}{|c|c|c|c|c|c|c|c|c|c|c|c|c|}
\hline Biossólidos $^{a}$ & $\mathrm{MO}$ & Carbono & Nitrogênio & C-solúvel & Açúcares & Proteína & Lipídeos & Hemicel. & Celulose & Lignina & Fenóis & Taninos \\
\hline & 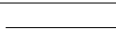 & $-\mathrm{g} \mathrm{kg}^{-1}$ & & $\% \mathrm{C}$ & & & & $\%$ & $\mathrm{MO}$ & & & \\
\hline BAC & 263,59 & 185,93 & 18,10 & 0,84 & 0,05 & 42,60 & 7,53 & 30,55 & 6,63 & 4,05 & 0,03 & 0,01 \\
\hline BAP & 553,55 & 311,55 & 42,08 & 0,84 & 0,02 & 41,60 & 7,97 & 17,50 & 4,76 & 30,21 & 0,03 & 0,02 \\
\hline BAS & 575,09 & 345,70 & 42,63 & 1,23 & 0,05 & 42,22 & 13,20 & 12,64 & 9,26 & 21,33 & 0,04 & 0,02 \\
\hline BLP & 536,81 & 314,80 & 27,18 & 0,46 & 0,04 & 27,65 & 4,15 & 4,59 & 28,57 & 30,63 & 0,07 & 0,04 \\
\hline CL & 398,94 & 217,45 & 17,40 & 0,24 & 0,03 & 25,38 & 2,61 & 3,25 & 39,67 & 21,96 & 0,07 & 0,04 \\
\hline
\end{tabular}

${ }^{a} \mathrm{BAC}=$ biossólido anaeróbio condicionado com cal e cloreto férrico; $\mathrm{BAP}=$ biossólido anaeróbio condicionado com polímero sintético; BAS = biossólido anaeróbio seco termicamente; BLP = biossólido proveniente de lagoas de estabilização e condicionado com polímero sintético; e CL = composto de lodo de esgoto obtido por compostagem em pilhas aeradas após mistura do BLP com bagaço de cana e restos de poda urbana.
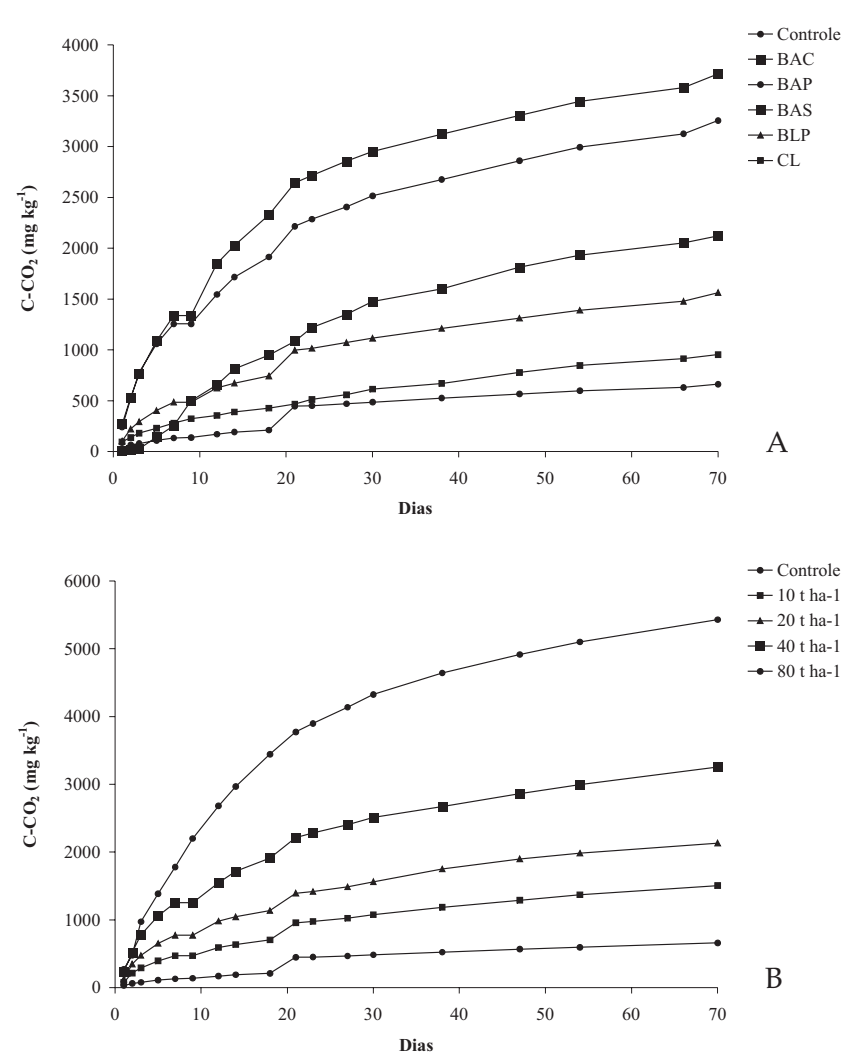

Figura 1. Quantidades de carbono emanado acumulado, na forma de $\mathrm{CO}_{2}\left(\mathrm{C}-\mathrm{CO}_{2}\right)$, a partir do solo controle e das misturas de solo e biossólidos, durante 70 dias de incubação: A- resultados dos cinco biossólidos na dose referência de $40 \mathrm{t} \mathrm{ha}^{-1} \mathrm{e}$; $\mathrm{B}$ - resultados do biossólido anaeróbio condicionado com polímero sintético (BAP) aplicado nas doses de 10, 20, 40, e $80 \mathrm{t} \mathrm{ha}^{-1}$.

A degradação da $\mathrm{MO}$ dos resíduos aplicados ao solo na dose de $40 \mathrm{t} \mathrm{ha}^{-1}$ foi semelhante entre os biossólidos provenientes do tratamento dos esgotos em sistema de lodos ativados (BAC, BAP e BAS), independentemente do processo de condicionamento para desidratação ou etapa complementar. O valor médio da taxa de degradação dos três biossólidos, após 70 dias de incubação, foi de 21,63\%. Taxas de degradação de biossólidos após aplicação no solo têm-se situado na faixa de $20 \%$ a $60 \%$ do total de C adicionado (TERRY et al., 1979; HSIEH, et al., 1981; WiSEMAN e ZiBILSKE, 1988; PIRES et al., 2002; SANTOS et al., 2002); lodos compostados podem ter valores abaixo de $20 \%$ (TESTER et al., 1977; BERNAL et al., 1998), considerando, em todos os casos, tempos de avaliação de até 130 dias. Tais valores são considerados baixos e indicam a presença predominante de compostos orgânicos recalcitrantes, isto é, de difícil degradação biológica no solo (TERRY et al., 1979; WiSEMAN e ZIBILSKE, 1988; MattiazZo et al., 1998; SANTOS et al., 2002).

Nos biossólidos BLP e CL constataram-se as menores taxas de degradação, respectivamente, 7,16 e 5,38 \% (Tabela 3). Menores taxas de degradação desses resíduos eram esperadas em função do processo de obtenção dos mesmos. O BLP é um biossólido com tempo de detenção de cerca de um ano em lagoas de decantação e posterior "fase aeróbia", em que o material é disposto em pilhas longitudinais revolvidas periodicamente durante 120 dias para à desidratação (Tabela 1). O CL tem a mesma origem do BLP, porém ao invés da desidratação, o biossólido foi misturado com bagaço de cana-de-açúcar e restos de poda urbana para compostagem durante 90 dias. Em ambos os casos, supõese que o material orgânico resultante seja biologicamente mais estabilizado, em comparação aos biossólidos de reator anaeróbio, e, por isso, com menor degradação após aplicação no solo. A compostagem de biossólidos possibilita a formação de substâncias húmicas mais estáveis, reduzindo a quantidade de C em compostos alifáticos e aumentando nos compostos aromáticos (PiotrowsKi et al., 1984), os quais são menos efetivos como substratos orgânicos e como fonte de energia aos microorganismos (HERNÁNDEZ-APAOLAZA et al., 2000). Também não se pode descartar a possibilidade de menor degradação do CL, em comparação ao BLP, pela simples mistura do bagaço de cana-de-açúcar e dos restos de poda urbana ao biossólido. TESTER et al. (1979) reportaram taxa média de degradação de 6,6\%, em 45 dias de incubação, para um composto orgânico obtido a partir de biossólido alcalino e cavacos de madeira (relação $2,5: 1$ ). 
Tabela 3. Taxas de degradação dos biossólidos após 70 dias de incubação. Valores médios de C-emanado e taxas de degradação ( \pm desvio padrão).

\begin{tabular}{lcccr}
\hline Biossólido & Dose & \multicolumn{2}{c}{ C-adicionado } & \multicolumn{2}{c}{ C-emanado } & \multicolumn{2}{c}{ Taxa de degradação } \\
\cline { 2 - 4 } & $\mathrm{t} \mathrm{ha}^{-1}$ & 7437,20 & $1636,47( \pm 17,69)$ & $22,00( \pm 0,24)$ \\
BAC & 40 & 12462,00 & $2592,78( \pm 185,77)$ & $20,81( \pm 1,49)$ \\
BAP & 40 & 13828,00 & $3054,51( \pm 97,47)$ & $22,09( \pm 0,70)$ \\
BAS & 40 & 12592,00 & $901,12( \pm 16,64)$ & $7,16( \pm 0,13)$ \\
BLP & 40 & 8698,00 & $467,84( \pm 7,54)$ & $5,38( \pm 0,09)$ \\
CL & 40 & 3115,50 & $846,53( \pm 22,28)$ & $27,17( \pm 0,72)$ \\
BAP & 10 & 6231,00 & $1472,56( \pm 35,63)$ & $23,63( \pm 0,57)$ \\
BAP & 20 & 24924,00 & $4768,20( \pm 30,86)$ & $19,13( \pm 0,12)$ \\
BAP & 80 & &
\end{tabular}

a $\mathrm{BAC}=$ biossólido anaeróbio condicionado com cal e cloreto férrico; $\mathrm{BAP}=$ biossólido anaeróbio condicionado com polímero sintético; BAS = biossólido anaeróbio seco termicamente; $\mathrm{BLP}=$ biossólido proveniente de lagoas de estabilização e condicionado com polímero sintético; e CL = composto de lodo de esgoto obtido por compostagem em pilhas aeradas após mistura do BLP com bagaço de cana e restos de poda urbana.

Com o aumento da dose do BLP houve redução da taxa de degradação, de $27,17 \%$ na dose $10 \mathrm{t} \mathrm{ha}^{-1}$, para $19,13 \%$ na dose $80 \mathrm{t} \mathrm{ha}^{-1}$. Embora as quantidades acumuladas de $\mathrm{C}-\mathrm{CO}_{2}$ tenham aumentado em função da dose do BLP aplicada (Figura 1B), tais aumentos não foram suficientes para manter inalterada a taxa de degradação, uma vez que esta última é calculada em relação ao total de C adicionado via dose do resíduo. Esse comportamento é consistente com outros resultados da literatura (Mattiazzo et al., 1998; Pires et al., 2002; Santos et al., 2002). O aumento do conteúdo orgânico adicionado, suplantando a capacidade microbiana de degradação (Wong et al., 1998), ou o maior aporte de C lábil com o aumento da dose do resíduo, gerando taxas respiratórias suficientemente elevadas no solo e, portanto, capazes de reduzir a concentração de oxigênio a patamares prejudiciais aos microrganismos aeróbios (Khalil et al., 2002), podem ser citados como possíveis responsáveis pelo decréscimo observado na taxa de degradação.

\subsection{Cinética de degradação da MO}

Os resultados médios de C-degradado foram ajustados satisfatoriamente aos modelos de cinética química com uma e duas fases (Tabela 4), porém não se ajustaram ao modelo com três fases.

Tabela 4. Parâmetros de cinética química e meia-vida de degradação (T1/2) obtidos a partir do ajuste dos dados de C-degradado a equações de cinética química de primeira ordem com uma e duas fases

\begin{tabular}{|c|c|c|c|c|c|c|c|c|c|c|}
\hline \multirow{2}{*}{ Biossólido ${ }^{a}$} & \multirow{2}{*}{ Dose } & \multicolumn{4}{|c|}{ C-degradado $=C_{0} \cdot\left(1-e^{-k \cdot t}\right)^{b}$} & \multicolumn{5}{|c|}{ C-degradado $=C_{1} \cdot\left(1-\mathrm{e}^{-\mathrm{k} 1 \cdot \mathrm{t}}\right)+\mathrm{C}_{2} \cdot\left(1-\mathrm{e}^{-\mathrm{k} 2 \cdot \mathrm{t}}\right)^{\mathrm{c}}$} \\
\hline & & $C_{0}$ & $k$ & $T 1 / 2^{d}$ & $r$ & $C_{1}$ & $k_{1}$ & $C_{2}$ & $k_{2}$ & $r$ \\
\hline & $\mathrm{t} \mathrm{ha}^{-1}$ & $\mathrm{mg} \mathrm{kg}^{-1}$ & $\mathrm{dia}^{-1}$ & dias & & $\mathrm{mg} \mathrm{kg}^{-1}$ & $\mathrm{dia}^{-1}$ & $\mathrm{mg} \mathrm{kg}^{-1}$ & $\mathrm{dia}^{-1}$ & \\
\hline BAC & 40 & 2143,94 & 0,0211 & 33 & 0,988 & 745,82 & 0,0211 & 1398,65 & 0,0211 & 0,988 \\
\hline BAP & 40 & 2369,45 & 0,0744 & 9 & 0,983 & 832,20 & 0,2809 & 1959,87 & 0,0305 & 0,998 \\
\hline BAS & 40 & 2889,36 & 0,0702 & 10 & 0,994 & s/ ajuste & s/ ajuste & s/ ajuste & s/ ajuste & s/ ajuste \\
\hline BLP & 40 & 799,26 & 0,0636 & 11 & 0,973 & 362,24 & 0,2138 & 1312,81 & 0,0075 & 0,998 \\
\hline CL & 40 & 588,30 & 0,0209 & 33 & 0,993 & 54,62 & 0,5490 & 947,34 & 0,0081 & 1,00 \\
\hline BAP & 10 & 779,02 & 0,0606 & 11 & 0,970 & 284,74 & 0,2813 & 922,04 & 0,0136 & 1,00 \\
\hline BAP & 20 & 1343,80 & 0,0706 & 10 & 0,970 & 537,93 & 0,2833 & 1318,19 & 0,0185 & 0,997 \\
\hline BAP & 80 & 4646,07 & 0,0621 & 11 & 0,998 & s/ ajuste & s/ ajuste & s/ ajuste & s/ ajuste & s/ ajuste \\
\hline
\end{tabular}

a BAC = biossólido anaeróbio condicionado com cal e cloreto férrico; BAP = biossólido anaeróbio condicionado com polímero sintético; BAS = biossólido anaeróbio seco termicamente; BLP = biossólido proveniente de lagoas de estabilização e condicionado com polímero sintético; e $\mathrm{CL}=$ composto de lodo de esgoto obtido por compostagem em pilhas aeradas após mistura do BLP com bagaço de cana e restos de poda urbana. ${ }^{\mathrm{b}} \mathrm{C}$-degradado $=\mathrm{C}_{0} \cdot\left(1-\mathrm{e}^{-\mathrm{k} . \mathrm{t}}\right)$. Em que: $\mathrm{C}$-degradado $\left(\mathrm{mg} \mathrm{kg}^{-1}\right)=$ carbono emanado como $\mathrm{CO}_{2}$ no tempo $\mathrm{t} ; \mathrm{C}_{0}\left(\mathrm{mg} \mathrm{kg}^{-1}\right)=$ carbono potencialmente mineralizável em 70 dias; $\mathrm{k}\left(\mathrm{dia}^{-1}\right)=$ constante de velocidade da reação de degradação do carbono; e $\mathrm{t}=$ tempo em dias.

${ }^{c} \mathrm{C}$-degradado $=\mathrm{C}_{1} \cdot\left(1-\mathrm{e}^{-\mathrm{k} 1 . \mathrm{t}}\right)+\mathrm{C}_{2} \cdot\left(1-\mathrm{e}^{-\mathrm{k} 2 . \mathrm{t}}\right)$. Em que: $\mathrm{C}$-degradado $\left(\mathrm{mg} \mathrm{kg}^{-1}\right)=$ carbono emanado como $\mathrm{CO}_{2}$ no tempo $\mathrm{t} ; \mathrm{C}_{1}\left(\mathrm{mg} \mathrm{kg}^{-1}\right)=$ carbono potencialmente mineralizável durante a primeira fase do processo de degradação; $k_{1}\left(\right.$ dia $\left.^{-1}\right)=$ constante de velocidade da reação de degradação do carbono durante a primeira fase; $C_{2}\left(\mathrm{mg} \mathrm{kg}^{-1}\right)=$ carbono potencialmente mineralizável durante a segunda fase do processo de degradação; $k_{2}=$ constante de velocidade da reação de degradação do carbono durante a segunda fase; e $t=$ tempo em dias.

${ }^{\mathrm{d}} \mathrm{T} 1 / 2$ = meia-vida de degradação, calculada pela expressão: T1/2 = ln $2 / \mathrm{k}$. 
Considerando os biossólidos aplicados na dose de $40 \mathrm{t} \mathrm{ha}^{-1}$; BAP, BAS e BLP tiveram valores da constante de velocidade de degradação (k) semelhantes, o que proporcionou valores de meia-vida de degradação (T1/2) também próximos, variando de 9 a 11 dias (Tabela 4). Os resíduos BAC e CL tiveram valores de $\mathrm{k}$ inferiores aos anteriormente citados, com correspondente valor de T1/2 igual a 33 dias. Menores valores de $\mathrm{k}$ ocorreram, provavelmente, devido ao maior grau de homogeneidade da fração orgânica do $\mathrm{CL}$ e, no caso do BAC, devido ao impacto inicial depressivo sobre a microbiota (lag-fase), cuja duração foi cerca de cinco dias, em que as parcelas com o biossólido apresentaram quantidades de $\mathrm{C}-\mathrm{CO}_{2}$ emanadas inferiores ou semelhantes ao controle. Wiseman e Zibilske (1988) observaram em função do tempo e da temperatura de incubação, e de diferenças nas propriedades químicas de biossólidos, que no período inicial de 11 dias de incubação houve emanação média de $\mathrm{C}-\mathrm{CO}_{2}$ correspondente a $70 \%$ do total medido durante todo o período de avaliação.

A aplicação do BAP nas quatro doses testadas não evidenciou alterações dos valores de $\mathrm{k}$ e, conseqüentemente, de $\mathrm{T} 1 / 2$, somente incrementos do $C$ potencialmente mineralizável $\left(C_{0}\right)$ com o aumento da dose (Tabela 4).

Com exceção do BAS, o ajuste à equação de cinética química com duas fases revelou que o processo de degradação da MO dos biossólidos foi caracterizado por uma fase inicial com elevada velocidade de degradação dos compostos orgânicos $\left(\mathrm{k}_{1}\right)$ presentes em quantidades limitadas $\left(\mathrm{C}_{1}\right)$, cuja exaustão do substrato ocorreu em poucos dias, e outra fase, posterior à primeira, com redução da velocidade da reação de degradação $\left(\mathrm{k}_{2}\right)$, em comparação com $\mathrm{k}_{1}$, e aumento da quantidade de carbono mineralizado $\left(\mathrm{C}_{2}\right)$. O BAC estava com valores iguais de $k_{1}$ e $k_{2}$, reflexo provavelmente da lag-fase induzida pelo resíduo. A diferença entre as velocidades de degradação do material orgânico dos resíduos, na primeira e segunda fases do processo pode ser percebida pelos valores da relação $k_{1} / k_{2}$. Esses valores foram de $1,9,28$ e 68, respectivamente para os biossólidos BAC, BAP, BLP e CL, sendo indicativo de quantas vezes a velocidade da primeira fase foi superior à da segunda fase. Nos biossólidos BLP e CL observaram-se os maiores contrastes entre as velocidades da reação de degradação. A duração da primeira fase de degradação, determinada graficamente a partir do modelo com duas fases e dos parâmetros de cinética mostrados na tabela 4 , foi de 20 dias para o BAC, 5 dias para o BAP, 7 dias para o BLP e, apenas, 2 dias para o CL. De modo geral, a primeira fase de degradação foi responsável por $20 \%$ a $35 \%$ do total de $\mathrm{C}-\mathrm{CO}_{2}$ emanado em 70 dias de incubação.

O conjunto de parâmetros e informações obtido a partir do ajuste dos dados às equações de cinética química permite afirmar que o BLP e o CL possuem MO mais estabilizada, em comparação aos demais biossólidos, apresentando ainda restrita quantidade de compostos prontamente degradáveis pela microbiota do solo.

As doses do biossólido BAP não influenciaram os valores de $k_{1}$ e $k_{2}$, somente de carbono emanado em cada fase $\left(C_{1}\right.$ e $\left.C_{2}\right)$, à semelhança do ocorrido na equação com fase única. Não foi possível o ajuste ao modelo com duas fases na maior dose do BAP. A duração da primeira fase de degradação também não foi alterada em função das doses, variando de 5 a 6 dias.

\subsection{Relação entre degradação e composição química da MO dos biossólidos}

A relação $\mathrm{C} / \mathrm{N}$ correlacionou negativamente com a taxa de degradação dos biossólidos após 70 dias de incubação $(r=-0,987)$, enquanto o QHL correlacionou positivamente $(r=0,950)$ (Tabela 5). Considerando que o QHL difere de outro índice testado, o ILC, por incluir a hemicelulose, pode-se afirmar que o conteúdo de hemicelulose nos resíduos é parâmetro importante na estimativa da degradação dos mesmos após aplicação no solo.

A correlação do teor de celulose com a taxa de degradação foi negativa $(r=-0,971)$, enquanto dessa última com a hemicelulose foi positiva $(r=$ 0,812 ) (Tabela 5). Tais resultados são coerentes em função da natureza mais recalcitrante da celulose em comparação à hemicelulose (BRADY e WEIL, 2002).

Outros compostos orgânicos correlacionados significativamente com a taxa de degradação foram: proteína bruta $(r=0,999)$, fenóis $(r=-0,969)$ e taninos $(r=-0,956)$. Compostos orgânicos nitrogenados como aminoácidos e proteínas representam fontes potenciais de carbono e nitrogênio devido à abundância na $\mathrm{MO}$ dos biossólidos e baixa relação C/N (Lerch et al., 1992). Além disso, microrganismos proteolíticos são de ocorrência generalizada em solos e biossólidos (Hankin e Hill, 1978; Loll e Bollag, 1983), confirmando a importância das proteínas como substrato para a atividade microbiana. No caso de fenóis e taninos, normalmente solúveis em água, estes podem formar complexos altamente resistentes com proteínas durante a decomposição de resíduos, resultando em redução das taxas de mineralização do C e do N (SAuvesty et al., 1992).

O C-solúvel em água também correlacionou positivamente $(r=0,935)$ com a taxa de degradação (Tabela 5). Porém, as quantidades de C-solúvel adicionadas via doses dos biossólidos não seriam suficientes para sustentar, sequer, toda a primeira fase de degradação (Figura 2), com maior importância, provavelmente, no início do processo. 
Tabela 5. Valores de coeficiente de correlação (r) e nível de significância (Prob. > t) das correlações simples entre os parâmetros de caracterização da fração orgânica, expressos como porcentagem do total de $\mathrm{MO}$ ou C-orgânico, e as taxas de degradação dos biossólidos ao final de 70 dias de incubação

\begin{tabular}{lccccc}
\hline Parâmetro & $\mathrm{r}$ & Prob. $>\mathrm{t}$ & Parâmetro & $\mathrm{r}$ & Prob. $>\mathrm{t}$ \\
\hline MO-total & $-0,000$ & 0,9875 & Açúcares & 0,285 & 0,6417 \\
C-total & 0,141 & 0,8203 & Proteína Bruta & 0,999 & 0,0000 \\
N-total & 0,528 & 0,3601 & Lipídeos & 0,850 & 0,0681 \\
C/N & $-0,987$ & 0,0018 & Hemicelulose & 0,812 & 0,0950 \\
C-solúvel & 0,935 & 0,0198 & Celulose & $-0,971$ & 0,0059 \\
Lignina /N & $-0,780$ & 0,1193 & Lignina & $-0,410$ & 0,4937 \\
ILC & 0,000 & 1,0000 & Fenóis & $-0,969$ & 0,0066 \\
RCO & 0,629 & 0,2557 & Taninos & $-0,956$ & $-0,0109$ \\
QHL & 0,950 & 0,0134 & - & - \\
\hline
\end{tabular}

ILC = índice lignocelulósico, calculado: lignina / (lignina + celulose);

$\mathrm{RCO}$ = razão de carbono oxidável, calculado: C-orgânico / C-Walkley e Black;

$\mathrm{QHL}=$ quociente holocelulose / lignocelulose, calculado: (hemicelulose + celulose) / (hemicelulose + celulose + lignina)

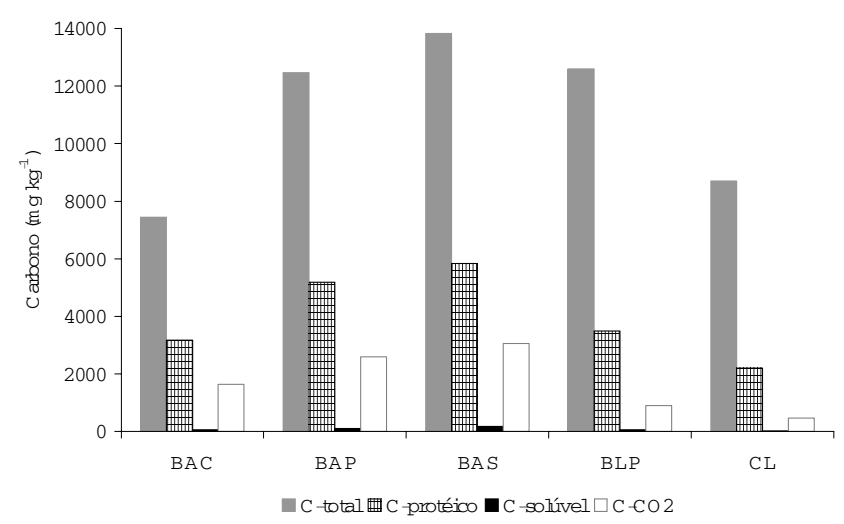

Figura 2. Quantidades adicionadas de carbono (C-total, C-protéico e C-solúvel) e emanadas como $\mathrm{CO}_{2}$ (C-CO2) nos tratamentos com $40 \mathrm{t} \mathrm{ha}^{-1}$ de biossólido.

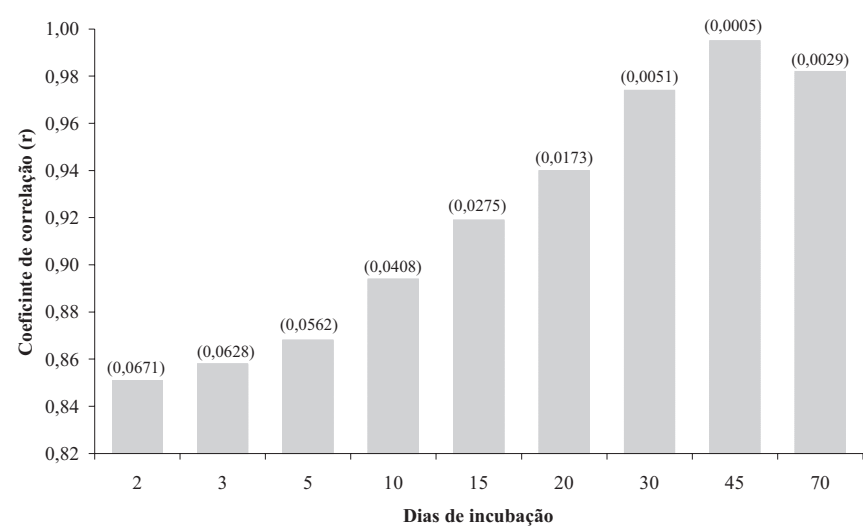

Figura 3. Valores de coeficiente de correlação (r) obtidos em correlações estatísticas entre as taxas de degradação dos biossólidos (após 2, 3, 5, 10, 15, 20, 30, 45 e 70 dias de incubação) e o teor inicial de proteína na matéria orgânica dos resíduos. Valores entre parênteses indicam a Prob > t.

Tabela 6. Equações matemáticas para previsão da taxa de degradação (y) dos biossólidos aplicados na dose de 40 t ha 11

\begin{tabular}{|c|c|c|c|c|c|}
\hline \multirow[t]{2}{*}{ Parâmetro (x) } & \multicolumn{2}{|c|}{ Equação $(y=a+b . x)$} & \multirow{2}{*}{ Parâmetro (x) } & \multicolumn{2}{|c|}{ Equação $(y=a+b . x)$} \\
\hline & $a$ & $b$ & & $a$ & $b$ \\
\hline $\mathrm{C} / \mathrm{N}$ & 50,22 & $-3,79$ & Fenóis ${ }^{b}$ & 34,67 & $-399,65$ \\
\hline QHL & $-10,13$ & 36,81 & Taninos ${ }^{b}$ & 31,15 & 602,56 \\
\hline C-solúvel & 0,57 & 20,16 & Proteína Bruta ${ }^{b}$ & $-19,76$ & 0,98 \\
\hline Celulose & 24,90 & $-0,53$ & - & - & - \\
\hline
\end{tabular}

Valor em porcentagem do total de C-orgânico;

Valor em porcentagem do total de MO.

A melhor correlação, altamente significativa $(\mathrm{P}<0,0001)$, foi obtida entre teor de proteína bruta e taxa de degradação $(\mathrm{r}=0,999)$. Adicionalmente, a quantidade de proteína bruta adicionada via biossólidos seria suficientemente elevada para explicar, sozinha, as diferenças na degradação da $\mathrm{MO}$ dos resíduos (Figura 2). Em função desses resultados, bem como da facilidade de quantificação dos teores de $\mathrm{MO}$ e de proteína bruta, esta última, expressa em relação ao conteúdo orgânico, deve ser considerada como variável promissora para fins de previsão da degradação de biossólidos pós-aplicação no solo. 
A partir das equações de cinética química com uma fase (Tabela 4), foram estimadas as quantidades de carbono degradado após $2,3,5,10,15,20,30,45$ e 70 dias de incubação e calculadas as taxas de degradação nessas épocas, para os biossólidos aplicados em dose correspondente a $40 \mathrm{t} \mathrm{ha}^{-1}$. As taxas foram, então, correlacionadas com o teor inicial de proteína nos resíduos, gerando os dados apresentados na Figura 3.

Os valores de $\mathrm{r}$ aumentaram com o tempo de incubação das amostras (Figura 3), indicando a crescente participação do carbono contido no pool protéico como substrato para o metabolismo microbiano (LERCH et al., 1992). O suprimento de carbono e energia para o metabolismo microbiano no início da incubação, provavelmente, contou com maior participação relativa de outros compostos de carbono mais lábeis.

$\mathrm{Na}$ tabela 6 são apresentadas as equações matemáticas para estimar a taxa de degradação de biossólidos, em função dos parâmetros correlacionados significativamente $(\mathrm{P}<0,05)$.

\section{CONCLUSÕES}

1. A MO dos biossólidos é constituída, predominantemente, por compostos recalcitrantes e, após aplicação no solo, a taxa de degradação é dependente da intensidade dos processos biológicos para estabilização da MO nas estações de tratamento de esgotos.

2. O processo de degradação ocorre em duas etapas: a primeira, intensa e de curta duração (média de 8 dias), em que compostos mais lábeis de carbono são exauridos; e a segunda etapa, menos intensa e responsável por mais de $65 \%$ do total de carbono orgânico degradado durante o período de 70 dias de avaliação.

3. O teor de proteína (expresso como porcentagem do total de MO) é promissor como variável preditora da taxa de degradação de biossólidos após aplicação no solo.

4. A participação do compartimento protéico no processo de degradação da MO é crescente com o tempo de incubação, comprovando que no início do período, outros compostos orgânicos mais lábeis funcionam como fonte de carbono e de energia para a microbiota edáfica.

\section{AGRADECIMENTOS}

Os autores agradecem a colaboração de toda equipe técnica do Laboratório de Biogeoquímica Ambiental do CENA/USP; à FAPESP pelo financiamento parcial desta pesquisa; e a Prof. ${ }^{a}$ Dr. ${ }^{a}$ Maria Emilia Mattiazzo-Prezotto, docente aposentada da USP e ex-responsável pelo Laboratório de Química Ambiental da ESALQ/USP, onde parte deste trabalho foi realizado.

\section{REFERÊNCIAS}

AJWA, H.A.; TABATABAI, M.A. Decomposition of different organic materials in soils. Biology and Fertility of Soils, Berlin, v.18, p.175-182, 1994.

ASSOCIATION OF OFFICIAL ANALYTICAL CHEMISTS. Official methods of analysis of the AOAC. 16.ed. Arlington, 1995. v.1, p.4/1-4/30.

BERNAL, M.P.;SÁNCHEZ-MONEDERO, M.A.; PAREDES, C.; ROIG, A. Carbon mineralization from organic wastes at different composting stages during their incubation with soil. Agriculture, Ecosystems and Environment, Amsterdam, v.69, p.175-189, 1998.

BERTONCINI, E.I. Comportamento de Cd, Cr, Cu, Ni e Zn em Latossolos sucessivamente tratados com biossólido: extração seqüencial, fitodisponibilidade e caracterização de substâncias húmicas. Piracicaba, 2002. 195f. Tese (Doutorado) - Escola Superior de Agricultura "Luiz de Queiroz", Universidade de São Paulo.

BRADY, N.; WEIL, R.R. The nature and properties of soils. 13.ed. Upper Saddle River: Prentice Hall, 2002. 960p.

CETESB - COMPANHIA DE TECNOLOGIA DE SANEAMENTO AMBIENTAL. Aplicação de biossólido em áreas agrícolas: critérios para projeto e operação São Paulo, 1999. 35p. (Manual Técnico).

FRANCO-HERNÁNDEZ, O.; MCKELLIGAN-GONZALEZ, A.N.; LOPEZ-OLGUIN, A.M.; ESPINOSA-CERON, F.; ESCAMILLA-SILVA, E.; DENDOOVEN, L. Dynamics of carbon, nitrogen and phosphorus in soil amended with irradiated, pasteurized and limed biosolids. Bioresource Technology, v.87, p.93-102, 2003.

GILMOUR, J.T.; ROMAN, F.; CLARK, M.D. Decomposition of biosolids in a disposal site soil. Journal of Environmental Quality, Madison, v.25, p.1083-1086, 1996.

HANKIN, L.; HILL, D.E. Proportion of bacteria in agricultural soils able to procedure degradative enzymes. Soil Science, Baltimore v.126, p.40-43, 1978.

HATTORI, H.; MUKAI, S. Decomposition of sewage sludge in soil as affected by their organic matter composition. Soil Science and Plant Nutrition, v.32, n.3, p.421-432, 1986.

HERNÁNDEZ-APAOLAZA, L.; GASCÓ, J.M.; GUERRERO, F. Initial organic matter transformation of soil amended with composted sewage sludge. Biology and Fertility of Soils, Berlin, v.32, p.421-426, 2000. 
HSIEH, Y.P.; DOUGLAS, L.A.; MOTTO, H.L. Modeling sewage sludge decomposition in soil: I. Organic carbon transformation. Journal of Environmental Quality, Madison, v.10, n.1, p.54-58, 1981.

KHALIL, M.I.; ROSENANI, A.B.; van CLEEMPUT, O.; BOECKX, P; SHAMAHUDDIN, J.; FAUZIAH, C.I. Nitrous oxide production from an Ultisol of the humid tropics treated with different nitrogen sources and moisture regimes. Biology and Fertility of Soils, Berlin, v.36, p.59-65, 2002.

LERCH, R.N.; BARBARICK, K.A.;SOMMERS, L.E.; WESTFALL, D.G. Sewage sludge proteins as labile carbon and nitrogen sources. Soil Science Society of America Journal, Madison, v.56, p.1470-1476, 1992.

LOLL, M.J.; BOLLAG. Protein transformation in soil. Advances in Agronomy, San Diego, v.36, p.351-382, 1983.

MATTIAZZO, M.E.; BARRETO, M.C.V.; RODELLA, A.A. Organic matter kinetics mineralization in soils amended with four different organic wastes. In: CONGRESS MONDIAL DE SCIENCE DU SOL, 16., Montpellier, 1998. Actes... Montpellier: ISSS, 1998. (CD-Rom)

PIOTROWSKI, E.G.; VALENTINE, K.M.; PFEFFER, P.E. Solidstate, ${ }^{13} \mathrm{C}$, cross-polarization, "magic-angle" spinning, NMR spectroscopy studies of sewage sludge. Soil Science, Baltimore, v.37, n.3, p.194-203, 1984.

PIRES, A.M.M.; ANDRADE, C.A.; MATTIAZZO, M.E. Degradação da carga orgânica, condutividade elétrica e pH de um Latossolo tratado com biossólido incorporado ou em superfície. In: FERTBIO2002, Rio de Janeiro, 2002. Resumos... Rio de Janeiro: UFRRJ, 2002. (CD-Rom)

RAIJ, van, B.; ANDRADE, J.C.; CANTARELLA, H.; QUAGGIO, J.A. (Eds.). Análise química para avaliação da fertilidade de solos tropicais. Campinas: Instituto Agronômico, 2001. 285p.

RODELLA, A.A.; SABOYA, L.V. Calibration for conductimetric determination of carbon dioxide. Soil Biology and Biochemistry, v.31, p.2059-2060, 1999.

SANTOS, D.S.; ANDRADE, C.A.; MATTIAZZO, M.E. Degradação da fração orgânica de lodos de esgoto após aplicação no solo. In: FERTBIO, Rio de Janeiro, 2002. Resumos... Rio de Janeiro: SBCS; SBM; UFFRJ, 2002. (CD-Rom)

SAUVESTY, A.; PAGE, F e HOUT, J. A simple method for extracting plant phenolic compounds. Canadian Journal Forest Research, Otawa, v.22, p.654-659, 1992.

SOMMERS, L.E.; NELSON, D.W.; SILVIERA, D.J. Transformations of carbon, nitrogen, and metals in soils treated with waste materials. Journal of Environmental Quality, Madison, v.8, p.287-294, 1979.

TERRY, R.E.; NELSON, D.W.; SOMMERS, L.E. Carbon cycling during sewage sludge decomposition in soils. Soil Science Society of America Journal, Madison, v.43, p.494-499, 1979.
TESTER, C.F.; SIKKORA, J.M.; TAYLOR, J.; PARR, J.F. Decomposition of sewage sludge compost in soil: III. Carbon, nitrogen, and phosphorus transformations in different sized fractions. Journal of Environmental Quality, Madison, v.8, n.1, p.79-82, 1979.

TESTER, C.F.; SIKKORA, J.M.; TAYLOR, J.; PARR, J.F. Decomposition of sewage sludge compost in soil. I. Carbon and nitrogen transformations. Journal of Environmental Quality, Madison, v.6, p.459-463, 1977.

VAN SOEST, P.J.; WINE, R.H. Use of detergent in the analysis of farmersfeeds. IV. Determination of plant cell wall constituents. Journal of Association of Official Analytical Chemistry, v.50, p.50-55, 1967.

WISEMAN, J.T.; ZIBILSKE, L.M. Effect of sludge application sequence on carbon and nitrogen mineralization in soil. Journal of Environmental Quality, Madison, v.17, n.2, p.334339, 1988.

WONG, J.W.C.; LAI, M.; FANG, M.; MA, K.K. Effect of sewage sludge amendment on soil microbial activity and nutrient mineralization. Environment International, Elmsford, v.24, n.8, p.935-943, 1998. 